\title{
What is the diagnostic value of dual-energy computed tomography in patients with clinical diagnosis of gout?
}

\author{
Jung Sun Lee* ${ }^{*}$ and Wook Jang Seo
}

\begin{abstract}
Objectives: To investigate the frequency of monosodium urate (MSU) crystal deposits on dual-energy computed tomography (DECT) in patients with clinical diagnosis of gout and the factors associated MSU crystal positivity.

Methods: This study was conducted in patients with clinical diagnosis of gout who underwent DECT. Clinical features were compared between patients with positive and those with negative DECT results. A logistic regression analysis was performed to determine the factors associated with MSU crystal positivity on DECT.

Results: A total of 148 patients with clinical diagnosis of gout were included, and MSU crystal deposition on DECT was observed in 64 patients (43.3\%). The patients with positive DECT results were more likely to have renal insufficiency, longer disease duration, and higher serum urate level than those with negative. In the multivariable analysis, first gout attack (odds ratio 0.462; 95\% confidence interval 0.229-0.931, $p=0.031$ ) was associated with a less likely MSU crystal deposit-positive DECT result. In the subgroup analysis of patients with first attack, serum urate level $>8 \mathrm{mg} / \mathrm{dL}$ was associated with DECT positivity.

Conclusion: Of the patients with clinical diagnosis of gout, those with renal insufficiency, longer disease duration, and high serum urate level were more likely to be positive of gout on DECT. First gout attack was associated with less likely to be positive for MSU crystal on DECT. Thus, performing DECT scan in the selected patients who had characteristics that highly probability of DECT positivity could increase positive predictive value.
\end{abstract}

Keywords: Monosodium urate, Gout, Dual-energy computed tomography, Diagnostic imaging

\section{Introduction}

Gout is caused by the deposition of monosodium urate (MSU) crystals in the joints, cartilage, and soft tissues. It is the most common inflammatory arthritis in the West, and its prevalence is constantly increasing in Korea [1]. An important test in diagnosing gout is to check for MSU crystals under polarizing microscopy through joint fluid aspiration in the affected joint [2]. However, in the case of the first metatarsal joint, puncture is not easy thus it may be difficult to confirm the presence of MSU crystals under polarizing microscopy. Furthermore, an

* Correspondence: jungsunlee0820@gmail.com

Division of Rheumatology, Department of Internal Medicine, Seoul Veterans Hospital, 53 Jinhwangdo-ro 61-gil Gangdong-gu, Seoul 05368, South Korea experienced inspector is required to detect MSU crystals under polarizing microscopy [3].

When the presence of MSU crystal deposits cannot be confirmed by synovial fluid examination, imaging could be used as a diagnostic tool in patients with suspected gout. Plain radiographs showed punched-out erosions with overhanging or sclerotic margins and tophi as illdefined mass lesions in chronic gout [4]. However, findings from plain radiographs are often normal, and the sensitivity of plain radiography for gout diagnosis is only $30 \%$ [5]. Recently, the use of ultrasonography in the diagnosis of gout has been increasing. The presence of MSU crystal deposits is suggested by the double-contour sign, tophus, and snowstorm appearance [6]. In addition, cortical bone erosion characterized by punched-out

(c) The Author(s). 2021 Open Access This article is licensed under a Creative Commons Attribution 4.0 International License, which permits use, sharing, adaptation, distribution and reproduction in any medium or format, as long as you give

appropriate credit to the original author(s) and the source, provide a link to the Creative Commons licence, and indicate if changes were made. The images or other third party material in this article are included in the article's Creative Commons licence, unless indicated otherwise in a credit line to the material. If material is not included in the article's Creative Commons licence and your intended use is not permitted by statutory regulation or exceeds the permitted use, you will need to obtain permission directly from the copyright holder. To view a copy of this licence, visit http://creativecommons.org/licenses/by/4.0/. 
lesions can be detected on ultrasonography [7]. However, ultrasonography highly depends on operator experience and patient factors, including obesity or the involved joint. Conventional computed tomography and magnetic resonance imaging can demonstrate erosion or tophi in gout, but these findings are not specific to gout [8].

Dual-energy computed tomography (DECT), which has been widely used in recent years, is a computerized tomography test that does not use a contrast agent. It is a noninvasive test that can identify soft tissues and MSU crystals using tissue-specific image attenuation. Its known sensitivity and specificity are $78-89 \%$ and 93$100 \%$, respectively [9-11]. Patients with short disease duration, with first gout attack, and taking uric acid-lowering drugs are known to most likely have false-negative test results for gout. In addition, in gout patients without tophi, the sensitivity of DECT is lower than in patients with tophi [12-15]. Thus, a negative result is difficult to interpret in patients with suspected gout.

Research is limited on whether clinical manifestations differ between positive and negative MSU crystals on DECT in patients with clinical diagnosis of gout, and on factors associated with the positive DECT results. Therefore, in this study, we aimed to examine the clinical characteristics of patients with positive MSU crystals on DECT in comparison with patients with negative MSU crystals and the factors associated with DECT positivity.

\section{Materials and methods}

\section{Study population}

In this retrospective cohort study, we reviewed the electronic medical records of patients who underwent DECT because of episode of inflammatory arthritis or tendinitis possibly caused by gout but could not undergo synovial fluid aspiration at Seoul Veterans Hospital, Seoul, South Korea, between January 2013 and March 2020. Clinical diagnosis of gout was on the basis of the 1977 or 2015 gout classification criteria [16, 17]. First, in accordance with the 2015 ACR/EULAR classification criteria, patients with a score of $\geq 8$ excluding DECT results were included as clinical diagnosis of gout cases. Among the patients with scores $<8$, those who met at least 6 or more of the 12 items of the 1977 ACR criteria were classified as having clinical diagnosis of gout. Patients taking urate-lowering agents (including allopurinol, febuxostat, or benzbromarone) were excluded from the analysis. From the medical records, the following data were collected: (1) demographic information, including age and sex; (2) data on accompanying medical conditions such as hypertension, diabetes mellitus, renal insufficiency (defined as an estimated glomerular filtration rate of < $60 \mathrm{~mL} / \mathrm{min} / 1.73 \mathrm{~m}^{2}$ obtained using the Chronic Kidney Disease Epidemiology Collaboration equation), cardiovascular disease, and alcohol intake; (3) affected joint, number of attacks, and disease duration; and (4) laboratory data, including serum urate levels and glomerular filtration rate.

This study was approved by the institutional review board of the Seoul Veterans Hospital, Seoul, Korea (IRB No. BOHUN 2020-07-012-001). The requirement for informed consent was waived owing to the retrospective nature of the study.

\section{DECT imaging scans}

All of the patients underwent DECT of the painful joint under the clinical suspicion of gout attack. A dualsource DECT scanner (Somaton Definition Flash, Siemens Healthcare) with $80 / \mathrm{Sn} 140 \mathrm{kV}$ and $250 \mathrm{mAs}$ for one tube and the other automatically adjusted to maintain a 2:1 ratio. All the datasets were reconstructed using a bone algorithm to $0.75-\mathrm{mm}$ slices with a $0.5-\mathrm{mm}$ increment. Post-processing was performed using a commercial software program ("gout," Syngo CT Workplace, Siemens Medical System). The MSU crystals were shown in green (Fig. 1a and b).

Erosion was defined as cortical disruption in any two planes (Fig. 1c and d). A musculoskeletal radiologist evaluated the DECT images and recorded the locations of the urate depositions.

\section{Statistical analyses}

The chi-square and Fisher exact tests were used for comparisons of categorical data between the 2 groups according to DECT results. Continuous values were expressed median (interquartile range ) using the MannWhitney $U$ test for comparing 2 groups of patients according to DECT results. A logistic regression analysis with a backward elimination procedure was performed to identify the factors associated with DECT positivity. Variables with $P$ values $<0.2$ in the univariate analysis were selected for the multivariable analysis. The SPSS 20.0 software (SPSS Inc., Chicago, IL, USA) was used for all the statistical analyses.

\section{Results}

Comparison of the MSU crystal deposit-positive and MSU crystal deposit-negative DECT groups

A total of 148 patients with clinical diagnosis of gout who underwent DECT were included. Among 148 included patients, 132 met the 2015 ACR/EULAR classification criteria excluding DECT results and 16 met the 1977 ACR criteria. Sixty-four patients had a first gout attack. Table 1 shows the baseline clinical characteristics and laboratory data of the included patients. Among the 148 patients, 64 had positive and 84 had negative DECT results for MSU crystal deposits. The mean age and sex distribution were similar between the 2 groups. No significant difference in the presence of comorbidities, 
A

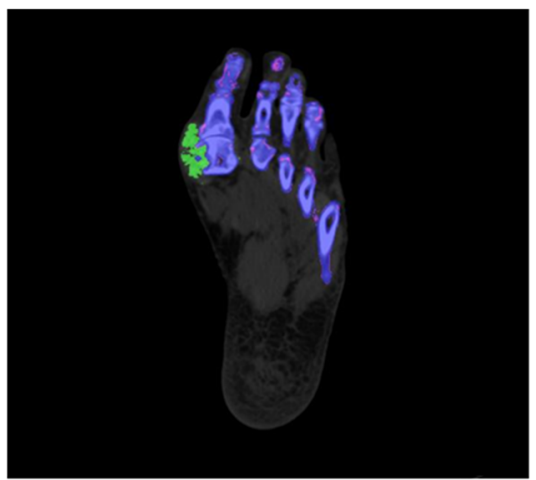

C

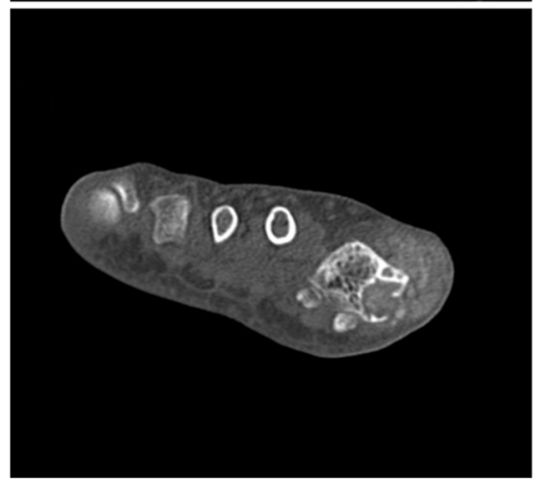

B

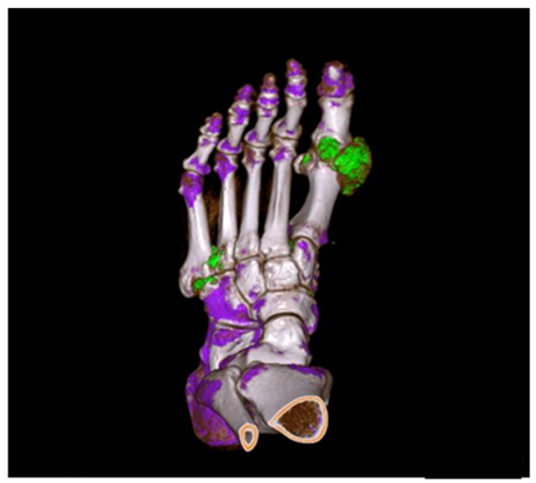

$\mathrm{D}$

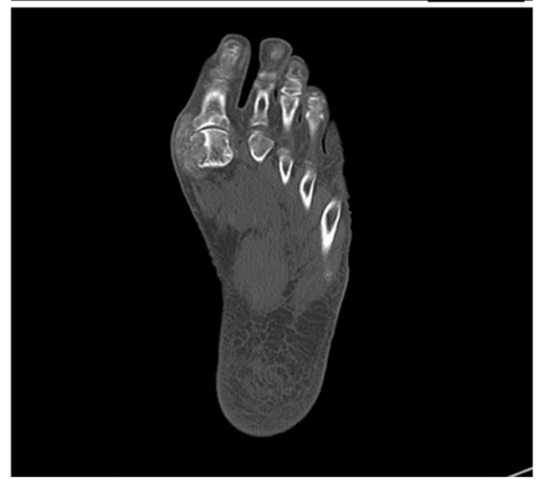

Fig. 1 Dual-energy computed tomography (DECT) images. A) Color mapping showing uric acid deposits (green) in the periarticular tissues of the first MTP joint. B) Three-dimensional DECT image with color mapping showing tophi (green) in the first MTP joint. C, D) Two-dimensional CT image showing high-attenuation tophi associated with erosions in the first MTP joint

including hypertension, diabetes mellitus, and cardiovascular disease, were found between the 2 groups. However, the patients with MSU crystal deposit- positive DECT results were more likely to have renal insufficiency $(29 / 64,45.3 \%$ vs. $20 / 84,23.8 \% ; P=0.006)$ and longer gout disease durations (38.5 months [3.3-120 months] vs. 5 months $[1.3-33.3$ months]; $P<0.001)$. Furthermore, among the patients with the MSU crystal deposit-positive DECT results, the proportion of those who had a first attack was lower $(21 / 64,32.8 \%$ vs. $43 / 84$, $51.2 \% ; P=0.025)$ than that among the patients with MSU crystal deposit-negative DECT results. The serum urate level was higher in the patients with positive than in those with negative DECT results for MSU crystal deposits. Among 16 patients who did not meet the 2015 gout classification criteria, 5 showed positive DECT result and met the 2015 ACR/EULAR classification criteria. Of 64 patients with positive DECT results, 60 started receiving urate-lowering agents after undergoing DECT.

\section{Factors associated with DECT positivity}

Table 2 shows the factors associated with DECT positivity. In the univariate analysis, age (odds ratio [OR] 1.043, 95\% confidence interval [CI] 1.008-1.078, $p=0.016$ ), renal insufficiency (OR 2.651, 95\% CI 1.313-5.356, $p=$
0.007), first gout attack (OR 0.446, 95\% CI 0.237-0.914, $p=0.026$ ), and serum urate level $>8 \mathrm{mg} / \mathrm{dL}$ were significantly associated with DECT positivity. In the multivariable analysis, first attack (OR 0.462, 95\% CI 0.229-0.931, $p=0.031$ ) was associated with DECT positivity.

\section{Comparison of the MSU crystal deposit-positive and MSU} crystal deposit-negative DECT groups in first attack Next, we focused the patients with first episode of inflammatory arthritis or tendinitis. Among the 64 patients with a first gout attack, 21 showed DECT-positive results for MSU crystal deposits (Table 3). Similarly to the total group, the frequencies of renal insufficiency and serum urate level were higher in the patients with positive than in those with negative DECT results for MSU crystal deposits. Erosion on DECT was detected in $38.1 \%(8 / 21)$ of the patients with positive and in $2.3 \%(1 /$ 43) of the patients with negative DECT results for MSU crystal deposits $(P<0.001)$.

\section{Factors associated with DECT positivity in the first gout attack}

Table 4 shows the factors associated with DECT positivity in the first attack group. In the univariate analysis, serum urate level $>8 \mathrm{mg} / \mathrm{dL}$ was significantly associated with DECT positivity (OR 3.472, 95\% CI 1.128-10.685, 
Table 1 Baseline characteristics of the patients with clinical diagnosis of gout

\begin{tabular}{|c|c|c|c|}
\hline Variable & $\begin{array}{l}\text { DECT (+) } \\
(n=64)\end{array}$ & $\begin{array}{l}\text { DECT (-) } \\
(n=84)\end{array}$ & $p$ \\
\hline Age (years) & $71(68.3-74)$ & $71(62.3-74)$ & 0.122 \\
\hline Male sex & $63(98.4)$ & $80(95.2)$ & 0.390 \\
\hline \multicolumn{4}{|l|}{ Comorbidity } \\
\hline Hypertension & $43(67.2)$ & $47(56.0)$ & 0.165 \\
\hline Diabetes mellitus & $12(18.8)$ & $19(22.6)$ & 0.567 \\
\hline Renal insufficiency & $29(45.3)$ & $20(23.8)$ & 0.006 \\
\hline Cardiovascular disease & $15(23.4)$ & $18(21.4)$ & 0.771 \\
\hline Alcohol intake & $4(6.2)$ & $11(13.1)$ & 0.172 \\
\hline Disease duration (months) & $38.5(3.3-120)$ & $5(1.3-33.3)$ & $<0.001$ \\
\hline \multicolumn{4}{|l|}{ Frequency of attack } \\
\hline First attack & $21(32.8)$ & $43(51.2)$ & 0.025 \\
\hline Three or more attacks/year & $11(17.2)$ & $11(13.1)$ & 0.488 \\
\hline \multicolumn{4}{|l|}{ Symptomatic joints } \\
\hline First MTP & $44(68.8)$ & $54(64.3)$ & 0.569 \\
\hline Midfoot & $11(17.2)$ & $18(21.4)$ & 0.520 \\
\hline Ankle & $8(9.8)$ & $8(10.8)$ & 0.828 \\
\hline Knee & $1(1.6)$ & $3(3.6)$ & 0.634 \\
\hline Hand & $0(0)$ & $5(6.0)$ & 0.070 \\
\hline Uric acid (mg/dL) & $8.7(7.7-9.5)$ & $8.1(6.8-9.1)$ & 0.013 \\
\hline GFR (ml/min/1.73m²) & $58(49-68.8)$ & $67(55-85.8)$ & 0.005 \\
\hline
\end{tabular}

Values are presented as number (\%), or median (interquartile range) DECT dual-energy computed tomography, MTP metatarsophalangeal, GFR Glomerular Filtration Rate $p=0.030$ ). In addition, age and renal insufficiency showed a tendency of association with DECT positivity. In the multivariable analysis, serum urate level $>8 \mathrm{mg} /$ dL (OR 3.180, 95\% CI 1.004-10.076, $p=0.049$ ) were associated with DECT positivity.

\section{Discussion}

In the present study, MSU crystals were detected in $43.2 \%$ of the patients with clinical diagnosis of gout by DECT. The characteristics of the patients with MSU crystal deposit-positive DECT results showed higher frequency of renal insufficiency, longer disease duration, and higher serum urate level than those with MSU crystal deposit-negative DECT results. First gout attack was associated with a less likely MSU crystal deposit-positive DECT result.

According to the European League Against Rheumatism guideline, an effort to confirm the diagnosis of gout on the basis of the presence of MSU crystals is required [18]. However, there is a limitation in performing joint fluid aspiration in small joints, including the first metatarsophalangeal joint. Clinical diagnosis of gout without joint aspiration could be uncertain, and the effort to search for MSU crystal deposition using imaging continues to be necessary. DECT scan is a noninvasive test to confirm the presence of MSU crystals. The known specificity of DECT is 93-95\% [19, 20]; thus, positive DECT results can be used in gout diagnosis. Furthermore, three-dimensional DECT color imaging of the MSU crystal could improve adherence to treatment with urate-lowering agents [21, 22]. However, the sensitivity is relatively low $[15,23]$, and the possibility of false-negative results should be considered. In a previous study, DECT showed high sensitivity in gout patients with tophi but low sensitivity in those without

Table 2 Factors associated with dual-energy computed tomography positivity

\begin{tabular}{|c|c|c|c|c|c|c|}
\hline & \multicolumn{3}{|c|}{ Univariate } & \multicolumn{3}{|c|}{ Multivariable } \\
\hline & OR & $\mathrm{Cl}$ & $P$ & OR & $\mathrm{Cl}$ & $P$ \\
\hline Age & 1.043 & $1.008-1.078$ & 0.016 & 1.030 & $0.994-1.069$ & 0.106 \\
\hline Male sex & 3.150 & $0.343-28.888$ & 0.310 & & & \\
\hline Hypertension & 1.612 & $0.819-3.171$ & 0.167 & & & \\
\hline Diabetes mellitus & 0.789 & $0.4351-1.774$ & 0.567 & & & \\
\hline Renal insufficiency & 2.651 & $1.313-5.356$ & 0.007 & 2.110 & $0.994-1.069$ & 0.055 \\
\hline Cardiovascular disease & 1.122 & $0.515-2.445$ & 0.771 & & & \\
\hline Disease duration & 1.004 & $1.000-1.008$ & 0.049 & & & \\
\hline Alcohol intake & 0.442 & $0.1134-1.460$ & 0.181 & & & \\
\hline First MTP joint involvement & 1.222 & $0.612-2.441$ & 0.570 & & & \\
\hline First attack & 0.446 & $0.237-0.914$ & 0.026 & 0.462 & $0.229-0.931$ & 0.031 \\
\hline Three or more attacks/year & 1.377 & $0.556-3.413$ & 0.489 & & & \\
\hline Uric acid $>8 \mathrm{mg} / \mathrm{dL}$ & 1.776 & $0.892-3.537$ & 0.028 & & & \\
\hline
\end{tabular}

$O R$ odds ratio, $C I$ Confidence interval, MTP metatarsophalangeal 
Table 3 Baseline characteristics of the patients with clinical diagnosis of gout (first attack)

\begin{tabular}{llll}
\hline Variable & $\begin{array}{l}\text { DECT (-) } \\
(\boldsymbol{n}=\mathbf{4 3})\end{array}$ & $\begin{array}{l}\text { DECT (+) } \\
(\boldsymbol{n}=\mathbf{2 1})\end{array}$ & $\mathbf{p}$ \\
\hline Age (years) & $71(59-74)$ & $72(68.5-80.5)$ & 0.149 \\
Male sex & $41(95.3)$ & $21(100)$ & 1.000 \\
Comorbidity & $23(53.5)$ & $15(71.4)$ & 0.170 \\
$\quad$ Hypertension & $9(20.9)$ & $6(28.6)$ & 0.540 \\
$\quad$ Diabetes mellitus & $10(23.3)$ & $10(47.6)$ & 0.048 \\
$\quad$ Renal insufficiency & $10(23.3)$ & $4(19.0)$ & 1.000 \\
$\quad$ Cardiovascular disease & $6(14.0)$ & $2(9.5)$ & 1.000 \\
Alcohol intake & $2(2-4)$ & $2(2-4.5)$ & 0.457 \\
Disease duration & $29(67.4)$ & $13(61.9)$ & 0.661 \\
First MTP & $7.6(6.4-8.5)$ & $8.6(7.4-9.5)$ & 0.045 \\
Uric acid & $72(33-86)$ & $60(49-74)$ & 0.078 \\
GFR & $1(2.3)$ & $8(38.1)$ & $<0.001$ \\
Erosion & $\begin{array}{l}\text { Values are presented as number (\%), or median (interquartile range) } \\
\text { DECT dual-energy computed tomography, MTP metatarsophalangeal, GFR } \\
\text { Glomerular Filtration Rate }\end{array}$
\end{tabular}

tophi [15]. In addition, another study reported various sensitivity rates (35.71-92.86\%) according to the first attack and early- and late-stage gout [14]. This indicates that the crystal size affects the sensitivity of DECT. In the present study, the proportion of positive MSU crystal deposition on DECT was $43.2 \%$, which is a relatively low value. As $>40 \%$ of the patients we included were having their first gout attack, the crystal size might not be large enough to be detected on DECT. On the other hand, although we included patients with clinical diagnosis of gout, some of them might not have true gout. Thus, interpreting whether negative DECT results indicate a false negative or no gout is difficult, and the diagnostic role of DECT is limited. Thus, performing DECT seems useful in patients with a high probability of positive DECT results.
In the present study, the frequencies of renal insufficiency and serum urate level were higher in the patients with MSU crystal-positive than in those with MSU crystal-negative DECT results. The association of renal insufficiency and gout is well known. Among the patients with gout, approximately $20 \%$ had a chronic kidney disease (CKD) [24], and gout is associated with a higher risk of CKD [25]. Furthermore, recently, uratelowering therapy has been found to be beneficial to renal function [26]. As two-thirds of urate is excreted by the kidney [27], patients with renal insufficiency might have a higher possibility of having a MSU crystal deposit in the affected joint.

A previous study reported that DECT positivity is associated with gout attack frequency [13]. In addition, short-term gout, especially the first attack, showed 35.7\% sensitivity [14]. In the present study, the patients having their first attack showed $32.8 \%$ positive rate, and first attack was associated with a less likely MSU crystal- positive DECT result. Previous studies have reported that patients with asymptomatic hyperuricemia also showed $15-24 \%$ positive rate of DECT [28, 29]. Although the positive rates in patients having their first attack were slightly higher than those in asymptomatic hyperuricemia, the diagnostic role of DECT is limited in patients having their first gout attack. Thus, DECT might not be recommended in patients with a first attack. However, in the 2020 American College of Rheumatology guideline, patients with a first attack with CKD stage $\geq 3$ or uric acid level $>9 \mathrm{mg} / \mathrm{dl}$ are recommended to start uratelowering therapy [30]. Indeed, in the subgroup analysis, the patients with a first attack and positive DECT results showed higher frequency of renal insufficiency and higher serum urate levels than those with negative results. Thus, in the first attack, performing a DECT scan in patients with hyperuricemia or CKD could increase the positive predictive value. In addition, the frequency of erosion was $38.1 \%$ in the patients with MSU crystal

Table 4 Factors associated with dual-energy computed tomography positivity (first attack)

\begin{tabular}{|c|c|c|c|c|c|c|}
\hline & \multicolumn{3}{|c|}{ Univariate } & \multicolumn{3}{|c|}{ Multivariable } \\
\hline & OR & $\mathrm{Cl}$ & $\mathbf{p}$ & OR & $\mathrm{Cl}$ & $\mathrm{p}$ \\
\hline Age & 1.058 & $0.998-1.121$ & 0.057 & 1.052 & $0.992-1.115$ & 0.089 \\
\hline Hypertension & 2.174 & $0.709-6.666$ & 0.174 & & & \\
\hline Diabetes mellitus & 1.511 & $0.456-5.009$ & 0.500 & & & \\
\hline Renal insufficiency & 3.000 & $0.988-9.111$ & 0.053 & & & \\
\hline Cardiovascular disease & 0.776 & $0.212-2.846$ & 0.703 & & & \\
\hline Disease duration & 0.997 & $0.950-1.047$ & 0.905 & & & \\
\hline Alcohol intake & 0.649 & $0.119-3.529$ & 0.617 & & & \\
\hline First MTP joint involvement & 1.222 & $0.612-2.441$ & 0.570 & & & \\
\hline Uric acid $>8 \mathrm{mg} / \mathrm{dL}$ & 3.472 & $1.128-10.685$ & 0.030 & 3.180 & $1.004-10.076$ & 0.049 \\
\hline
\end{tabular}

OR odds ratio, $\mathrm{Cl}$ Confidence interval, MTP metatarsophalangeal 
deposits in the first gout attack. In a previous study, DECT demonstrated a high reproducibility for joint erosion. The erosion was positively correlated with MSU crystal volume and indicated a high disease severity that might require intensive urate-lowering therapy [31]. Thus, in selective patients with a suspicious first gout attack, including hyperuricemia or CKD, performing DECT could provide more information about erosion and MSU crystal deposition.

The present study has some limitations. The presence of MSU crystals could not be confirmed on polarizing microscopy; thus, we could not evaluate the sensitivity or specificity of DECT for the diagnosis of gout in our cohort. Furthermore, false-positive or false-negative DECT results are also possible. Second, because of the single-center retrospective design of the study, the generalizability of the study results is limited. For example, the ages of the included patients were older than the expected age for gout.

\section{Conclusion}

The positivity rate by DECT was $43.2 \%$ in the patients with clinical diagnosis of gout and decreased more in the patients having their first gout attack. Positive DECT results were more frequently observed in patients with chronic kidney disease and hyperuricemia. When DECT demonstrates negative MSU crystal finding, diagnostic role of DECT is limited. Thus, performing DECT in selected patients with characteristics that have high probability of DECT positivity could increase the diagnostic value of DECT.

\section{Abbreviations}

CKD: Chronic kidney disease; Cl: Confidence interval; CT: Computed tomography; DECT: Dual-energy computed tomography; MSU: Monosodium urate; OR: Odds ratio

\section{Acknowledgements}

The authors would like to thank Enago (http://www.enago.co.kr) for the English language review.

\section{Authors' contributions}

JSL contributed to data acquisition, data analysis and interpretation, article writing. WJS contributed to study design and article review. All authors take full responsibility for the integrity of the study and approved the final version of the manuscript.

\section{Authors' information}

Not applicable.

\section{Funding}

This study was supported by a VHS Medical Center Research Grant, Republic of Korea (VHSMC 20046)

Availability of data and materials Not applicable.

\section{Declarations}

Ethics approval and consent to participate

This study was approved by the institutional review board of the Seoul Veterans Hospital, Seoul, Korea (IRB No. BOHUN 2020-07-012-001).

\section{Consent for publication}

Not applicable.

\section{Competing interests}

The authors declare that they have no competing interests.

Received: 24 February 2021 Accepted: 16 June 2021

Published online: 29 June 2021

\section{References}

1. Kuo CF, Grainge MJ, Zhang W, Doherty M. Global epidemiology of gout: prevalence, incidence and risk factors. Nat Rev Rheumatol. 2015;11(11):64962. https://doi.org/10.1038/nrrheum.2015.91.

2. Neogi T, Jansen TL, Dalbeth N, Fransen J, Schumacher HR, Berendsen D, et al. 2015 gout classification criteria: an American College of Rheumatology/European league against rheumatism collaborative initiative. Arthritis Rheum. 2015;67(10):2557-68. https://doi.org/10.1002/art.39254.

3. Dieppe P, Swan A. Identification of crystals in synovial fluid. Ann Rheum Dis. 1999;58(5):261-3. https://doi.org/10.1136/ard.58.5.261.

4. Perez-Ruiz F, Dalbeth N, Urresola A, de Miguel E, Schlesinger N. Imaging of gout: findings and utility. Arthritis Res Ther. 2009;11(3):232.

5. Rettenbacher T, Ennemoser S, Weirich H, Ulmer H, Hartig F, Klotz W, et al. Diagnostic imaging of gout: comparison of high-resolution US versus conventional X-ray. Eur Radiol. 2008;18(3):621-30. https://doi.org/10.1007/ s00330-007-0802-z.

6. Ogdie A, Taylor WJ, Neogi T, Fransen J, Jansen TL, Schumacher HR, et al. Performance of ultrasound in the diagnosis of gout in a multicenter study: comparison with monosodium urate monohydrate crystal analysis as the gold standard. Arthritis Rheum. 2017;69(2):429-38. https://doi.org/10.1002/a rt.39959.

7. Wu M, Liu FJ, Chen J, Chen L, Wei C, Hu ZM, et al. Prevalence and factors associated with bone Erosion in patients with gout. Arthritis Care Res. 2019; 71(12):1653-9. https://doi.org/10.1002/acr.23816.

8. Chou H, Chin TY, Peh WCG. Dual-energy $C T$ in gout - a review of current concepts and applications. J Med Radiat Sci. 2017;64(1):41-51. https://doi. org/10.1002/jmrs.223.

9. Spermon J, Van Dijke CF. Dual energy CT: added value in gouty arthritis. Jbr-btr. 2013;96(1):34-7. https://doi.org/10.5334/jbr-btr.179.

10. Girish G, Melville DM, Kaeley GS, Brandon CJ, Goyal JR, Jacobson JA, et al. Imaging appearances in gout. Arthritis. 2013;2013:673401.

11. Mallinson PI, Reagan AC, Coupal T, Munk PL, Ouellette H, Nicolaou S. The distribution of urate deposition within the extremities in gout: a review of 148 dual-energy CT cases. Skelet Radiol. 2014;43(3):277-81. https://doi.org/1 0.1007/s00256-013-1771-8

12. Bongartz T, Glazebrook KN, Kavros SJ, Murthy NS, Merry SP, Franz WB 3rd, et al. Dual-energy $C T$ for the diagnosis of gout: an accuracy and diagnostic yield study. Ann Rheum Dis. 2015;74(6):1072-7. https://doi.org/10.1136/a nnrheumdis-2013-205095.

13. Gamala M, Linn-Rasker SP, Nix M, Heggelman BGF, van Laar JM, Pasker-de Jong PCM, et al. Gouty arthritis: decision-making following dual-energy CT scan in clinical practice, a retrospective analysis. Clin Rheumatol. 2018;37(7): 1879-84. https://doi.org/10.1007/s10067-018-3980-y.

14. Jia E, Zhu J, Huang W, Chen X, Li J. Dual-energy computed tomography has limited diagnostic sensitivity for short-term gout. Clin Rheumatol. 2018;37(3): 773-7. https://doi.org/10.1007/s10067-017-3753-z.

15. Baer AN, Kurano T, Thakur UJ, Thawait GK, Fuld MK, Maynard JW, et al. Dualenergy computed tomography has limited sensitivity for non-tophaceous gout: a comparison study with tophaceous gout. BMC Musculoskelet Disord. 2016;17(1):91. https://doi.org/10.1186/s12891-016-0943-9.

16. Neogi T, Jansen TLTA, Dalbeth N, Fransen J, Schumacher HR, Berendsen D, et al. 2015 gout classification criteria: an American College of Rheumatology/European league against rheumatism collaborative initiative. Ann Rheum Dis. 2015;74(10):1789-98. https://doi.org/10.1136/a nnrheumdis-2015-208237. 
17. Wallace SL, Robinson H, Masi AT, Decker UL, McCarty DJ, Yü TF. Preliminary criteria for the classification of the acute arthritis of primary gout. Arthritis Rheum. 1977;20(3):895-900. https://doi.org/10.1002/art.1780200320.

18. Richette P, Doherty M, Pascual E, Barskova V, Becce F, Castaneda J, et al. 2018 updated European league against rheumatism evidence-based recommendations for the diagnosis of gout. Ann Rheum Dis. 2020;79(1):318. https://doi.org/10.1136/annrheumdis-2019-215315.

19. Lee YH, Song GG. Diagnostic accuracy of dual-energy computed tomography in patients with gout: a meta-analysis. Semin Arthritis Rheum. 2017;47(1):95-101. https://doi.org/10.1016/j.semarthrit.2017.03.002.

20. Kiefer T, Diekhoff T, Hermann S, Stroux A, Mews J, Blobel J, et al. Single source dual-energy computed tomography in the diagnosis of gout: diagnostic reliability in comparison to digital radiography and conventional computed tomography of the feet. Eur J Radiol. 2016;85(10):1829-34. https://doi.org/10.1016/.jejrad.2016.08.004

21. Breuer GS, Bogot N, Nesher G. Dual-energy computed tomography as a diagnostic tool for gout during intercritical periods. Int J Rheum Dis. 2016; 19(12):1337-41. https://doi.org/10.1111/1756-185X.12938.

22. Desai MA, Peterson JJ, Garner HW, Kransdorf MJ. Clinical utility of dualenergy CT for evaluation of tophaceous gout. Radiographics. 2011;31(5): 1365-75; discussion 76-7. https://doi.org/10.1148/rg.315115510.

23. Huppertz A, Hermann K-GA, Diekhoff T, Wagner M, Hamm B, Schmidt WA Systemic staging for urate crystal deposits with dual-energy $C T$ and ultrasound in patients with suspected gout. Rheumatol Int. 2014;34(6):76371. https://doi.org/10.1007/s00296-014-2979-1.

24. Zhu Y, Pandya BJ, Choi HK. Comorbidities of gout and hyperuricemia in the US general population: NHANES 2007-2008. Am J Med. 2012;125(7):679-87.e1.

25. Singh JA, Cleveland JD. Gout is associated with a higher risk of chronic renal disease in older adults: a retrospective cohort study of U.S. Medicare population. BMC Nephrol. 2019;20(1):93.

26. Levy G, Shi JM, Cheetham TC, Rashid N. Urate-lowering therapy in moderate to severe chronic kidney disease. Perm J. 2018;22:17-142. https://doi.org/10. 7812/TPP/17-142.

27. Maiuolo J, Oppedisano F, Gratteri S, Muscoli C, Mollace V. Regulation of uric acid metabolism and excretion. Int J Cardiol. 2016;213:8-14. https://doi. org/10.1016/j.jjcard.2015.08.109.

28. Dalbeth N, House ME, Aati O, Tan P. Franklin C, Horne A, et al. Urate crystal deposition in asymptomatic hyperuricaemia and symptomatic gout: a dual energy CT study. Ann Rheum Dis. 2015;74(5):908-11. https://doi.org/10.113 6/annrheumdis-2014-206397.

29. Wang P, Smith SE, Garg R, Lu F, Wohlfahrt A, Campos A, et al. Identification of monosodium urate crystal deposits in patients with asymptomatic hyperuricemia using dual-energy CT. RMD Open. 2018;4(1):e000593. https:// doi.org/10.1136/rmdopen-2017-000593.

30. FitzGerald JD, Dalbeth N, Mikuls T, Brignardello-Petersen R, Guyatt G, Abeles AM, et al. 2020 American College of Rheumatology Guideline for the Management of Gout. Arthritis Care Res. 2020;72(6):744-60. https://doi.org/1 $0.1002 / a c r .24180$

31. Dalbeth N, Nicolaou S, Baumgartner S, Hu J, Fung M, Choi HK. Presence of monosodium urate crystal deposition by dual-energy $\mathrm{CT}$ in patients with gout treated with allopurinol. Ann Rheum Dis. 2018;77(3):364-70. https:// doi.org/10.1136/annrheumdis-2017-212046.

\section{Publisher's Note}

Springer Nature remains neutral with regard to jurisdictional claims in published maps and institutional affiliations.

Ready to submit your research? Choose BMC and benefit from:

- fast, convenient online submission

- thorough peer review by experienced researchers in your field

- rapid publication on acceptance

- support for research data, including large and complex data types

- gold Open Access which fosters wider collaboration and increased citations

- maximum visibility for your research: over $100 \mathrm{M}$ website views per year

At BMC, research is always in progress.

Learn more biomedcentral.com/submissions 